\title{
Application of Fuzzy Cognitive Map within educational context: A review over the past five
}

\author{
years. \\ [Siti Soraya Abdul Rahman1 \\ Behzad Mahaseni2 \\ Rukaini Abdullah3]
}

\begin{abstract}
A traditional cognitive map has been extended to what is known as FCM, acronym for Fuzzy Cognitive Map. FCM combines two popular soft computing techniques, namely fuzzy logic and neural network. FCM has emerged as knowledge representation and reasoning technique for modeling causal complex problems with inherent uncertainties. Indeed, past research has shown that FCM has been successfully applied in various domain such as computer science, medicine, education, and others. Application of FCM in education such as mathematic or science are very diverse, from student modeling to diagnosing student's misconception in learning and from assessing processes in teaching-learning to identifying learning-styles preference. This paper reviews the most recent application of FCM within educational context over the past five years and analyzed them based on the educational problem addressed, areas within education domain, problem-solving paradigm, and limitations. The discussion follows from the summary of the analysis and finally suggests direction for further improvement.
\end{abstract}

Keywords-Fuzzy cognitive map, knowledge representation, education

\section{Introduction}

Application of FCM in education such as mathematic or science are very diverse, from student modeling to diagnosing student's misconception in learning and from assessing processes in teaching-learning to identifying learning-styles preference. This paper reviews the most recent application of FCM in education. Domain knowledge representation is the most important component of an online

Author no. 1

Department of Artificial Intelligence

Faculty of Computer Science and Information Technology

University of Malaya

Malaysia

Author no. 2

Department of Artificial Intelligence

Faculty of Computer Science and Information Technology

University of Malaya

Malaysia

Author no. 3

Department of Artificial Intelligence

Faculty of Computer Science and Information Technology

University of Malaya

Malaysia learning system, particularly adaptive learning environment. The representation in this context refers to the representation of subject matter expert knowledge and learner's understanding of the subject. This implies that the domain knowledge representation plays a significant role in the ability of the system to model the learner's prior knowledge and misconceptions.

FCMs are defined based on graph theory concepts, which are inference networks with great potential for representing knowledge and reasoning. More specifically, FCM is a cognition graph designed to model causal complex problems with inherent uncertainties. FCM (as introduced by Kosko [1]) is an extended form of knowledge representation and reasoning technique and originated from a traditional cognitive map proposed by Axelrod [2]. The technique combines fuzzy logic concepts and neural networks and consists of nodes known as concepts representing elements of the FCM model. The directed lines labelled with fuzzy values show the relationship strength between the nodes.

Sec. II provides a brief review of FCM and an overview of various application of FCM that spans across scientific domains while Sec. III provides a brief review of the most recent application of FCMs within educational context over the past five years, from the year 2013 onwards. Sec. IV discusses the limitations of the current applications of FCM and provides some directions for future improvement. Finally, Sec. V concludes the paper.

\section{An overview of Fuzzy Cognitive Map}

\section{A. Fuzzy Cognitive Map}

FCM represents a model of a given system by a directed graph depicting relationship among concepts. Nodes in FCM represent the concepts that describe the system's behaviour. The connections between concepts represent the causal relationships between the concepts in the real world. These connections are modeled through weighted edges between concepts of the graph. Both the concepts and edges values in FCM closely follow the ideas in Fuzzy Logic. In Figure 1, an example of FCM is shown where the concepts are defined as $C_{i}$ where $C_{i} \in[0,1]$, ie $[0, N]$ and $\mathrm{N}$ is the number of concepts. The value of each edge between concepts of

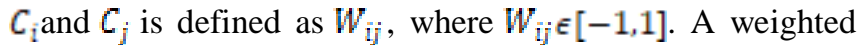
edge represents the degree and direction of which one concept influences another concept. While the '-1' weight value shows the strongest negative interrelation, the ' +1 ' weight value shows the strongest positive interrelation. 


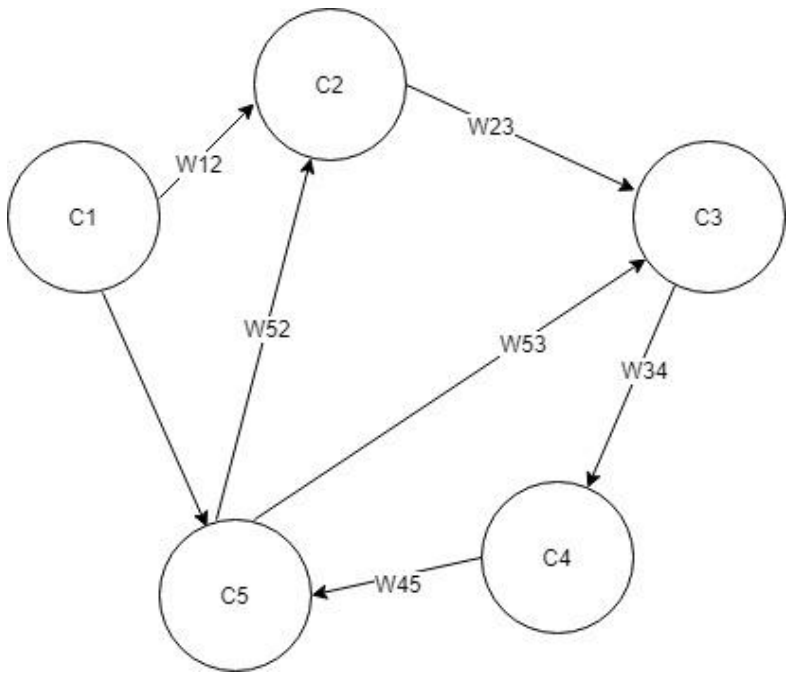

Figure 1 Typical Fuzzy Cognitive Map

Each concept value is determined by the value of the concept associated with it and is calculated using the following equation:

$$
A_{i}(k+1)=f\left(A_{i}(k)+\sum_{j \neq i j=1}^{W} A_{j}(k) \cdot W_{i j}\right)
$$

Where, $f$ is the transformation function, $A_{i}(k)$ is the concept $C_{i}$ value at iteration $\mathrm{k}$, and $A_{i}(k+1)$ is the $C_{i}$ value at iteration $(\mathrm{k}+1)$. The transformation function is used to constraint the values to be in a certain desired intervals. Table 1 shows a list of commonly used transfer functions.

Table 1

\begin{tabular}{|l|l|}
\hline Function & Equation \\
\hline Bivalent & $f_{\text {gign }}(x)= \begin{cases}0 & x \leq 0 \\
1 & x>0\end{cases}$ \\
\hline Trivalent & $f_{\text {tri }}(x)= \begin{cases}-1 & x \leq-0.5 \\
0 & 0.5 \leq x<0.5 \\
+1 & x>0.5\end{cases}$ \\
\hline Sigmoid & $f(x)=\frac{1}{1+e^{-\infty x}} \quad \alpha \geq 0$
\end{tabular}

In practice, experts from each scientific area are responsible for the development of FCM.

\section{B. Application of FCM in scientific fields}

During the past years, FCMs are applied in several scientific fields, such as medicine, environment, engineering, information technology, social, expert systems, robotics, and others. In addition, according to Chen et.al. [4], FCMs are also solved problems such as business intelligence system, reliability within the plant personnel, key success factors of IT projects, construction of IT project execution risk model, solar industry, medical treatment, supplier selection issues, business process performance measures, air freight forwarders, city sustainability policy, higher education blended-learning environment, ecommerce recommendation system and others. In summary, FCMs are applicable in several problem-solving paradigms such as decision-making, prediction, diagnosis, selection, planning, and modeling.

\section{Development of FCM}

Three approaches have been implemented to define FCM models [3]:

1. Manual: This approach is the standard way of defining FCMs and it relies on the expert's knowledge. In other words, given the domain knowledge of the expert and his/her expertise, the expert defines the concepts and their relations as well assigned values for each concept and weight strength. The main issue with this approach is that it is strongly relies on the manual process of defining the model and it is hard to assess the accuracy of the defined model.

2. Semi-automated: The limitations in the manual approach encouraged the researchers to use the historical data for learning FCM structure which includes the relations between the concepts and their weights. Note that although these approaches require less intervention from humans they still depend on human expertise to define the concepts.

3. Automated: These approaches use learning techniques to exploit the information in the historical data and use that to define the concepts and their relations.

It is important to note that past researchers have pointed out several limitations of the conventional FCMs. The limitations as discussed in [5] is as follows:

1. In FCM models, the effect of a relationship is not always immediate. It takes some time to see the effect of a concept in another concept. A situation known as time delay in the interaction between concepts.

2. Originally, FCM only support a linear model for the connection between to concepts. This limits the ability of FCM to model more complex (non-linear) relationships between concepts.

3. FCM does not support logical operations (e.g. AND, OR) between concepts.

4. FCM is not capable of modeling multi-meaning concepts. These are referred as the gray concepts in the literature.

5. FCM concepts are not multistate (i.e. quantum). A concept in FCM cannot have multiple values.

6. FCM model cannot handle more than one relationship between concepts.

7. In real-world scenarios, many of the causal connections are not monotonic or symmetric. 
Past researchers have proposed several extensions to conventional FCMs to overcome the above limitations, as discussed in [5]. These include the following extensions:

1. Rule-Based Fuzzy Cognitive Maps

2. Fuzzy Grey Cognitive Maps

3. Intuitionistic Fuzzy Cognitive Maps

4. Dynamical Cognitive Networks

5. Dynamic Random Fuzzy Cognitive Maps

6. Fuzzy Cognitive Networks

7. Evolutionary Fuzzy Cognitive Maps

8. Fuzzy Time Cognitive Maps

9. Fuzzy Rules incorporated in Fuzzy Cognitive Maps

10. Belief-Degree-Distributed Fuzzy Cognitive Maps

11. Rough Cognitive Maps

12. Time Automata-Based Fuzzy Cognitive Maps FCMs

\section{Review on the application of FCM in education}

There are several studies on the application of FCMs in education during the last five years.

- Chrysafiadi \& Virvou (2015) applied fuzzy knowledge state definer (a method based on fuzzy cognitive maps) to personalize programming instruction for each student. Their goal is to provide students with an interactive assistance, which helps them to achieve maximum learning gain.

- Takács, Rudas, \& Lantos (2014) proposed FCM for student grade evaluation and prediction. In addition, they also studied the correlation and the strength between the factors (e.g. average grade, scholarship index, completed credit points, and others) in an educational IT system known as Neptune system.

- Bagány \& Takács (2017) implemented FCM for analyzing the parameters of an educational model in a school system. The main purpose of their study is to evaluate the correlations between the results of students' final exam and their study results. They believe that the study subjects that affect the student learning are almost the same even if the educational environments are different. The educational environments differences are, such as the country, families, teachers, schools, school systems, the economic situation, the organization of the education system, the financial support of the state, and others.

- Baron, Rojas, Diaz, \& Contreras (2014) used FCM for learning assessment system. They applied Hebbian rules to learn the FCM weights and update them in an interactive environment for teaching. The system uses an algorithm to determine if there exists graph isomorphism between the graph built by the teacher and the students' graph, built as a result of their interaction with the system.

- $\quad$ Albayrak \& Albayrak (2016) applied FCM to assess the effect of practical courses such as robotics on students' learning achievements in schools. In their work, non-Linear Hebbian learning algorithm has been used for training of the weight matrix. From the comparison of the results obtained from FCM before and after the development processes of robots, it was observed that students' learning achievement has dramatically increased.

- Yesil, Ozturk, Dodurka, \& Sahin (2013) construct FCM to model the success factors of an academic program. In their work, FCM is used for modeling critical success indicators for the Control Engineering Program (CEP). These indicators are important for the university to achieve its goal to improve the program outcomes.

- Aguilar, Valdiviezo-Díaz (2016) suggested an intelligent recommender system based on the FCM model, augmented with a supervised learning approach for smart school learning resources. This recommender system exploits other information and learn or discover new knowledge.

- $\quad$ Nayak, P., Madireddy, S., Case, D. M., \& Stylios, C. D. (2017) proposes FCM to predict desirability of university along with number of applications for university admission. Student applications are affected by the variety of factors including university reputation, country selection, availability of scholarships, student services and others.

Table 2 summarized the studies based on the educational problem addressed, subject areas and/or systems within education domain, problem-solving paradigm, and limitations. 
Proc. of the Sixth Intl. Conf. Advances in Computing, Communication and Information Technology- CCIT 2018

Copyright (C) Institute of Research Engineers and Doctors, USA. All rights reserved.

ISBN: 978-1-63248-149-8 doi: 10.15224/978-1-63248-149-8-21

Table 2

\begin{tabular}{|c|c|c|c|c|c|}
\hline $\begin{array}{l}\text { Subject areas / } \\
\text { systems }\end{array}$ & Education problem & Problem-solving paradigm & Limitation & FCM extension & $\begin{array}{c}\text { Year of } \\
\text { publication }\end{array}$ \\
\hline Programming & Personalized tutoring & Student modeling & Manual & $\begin{array}{l}\text { FuzKSD (Rule-based } \\
\text { fuzzy logic system) }\end{array}$ & $\begin{array}{l}\text { (Chrysafiadi \& } \\
\text { Virvou, 2015)[6] }\end{array}$ \\
\hline $\begin{array}{l}\text { Educational IT } \\
\text { system, Neptune } \\
\text { System }\end{array}$ & $\begin{array}{l}\text { Student grade evaluation and } \\
\text { prediction }\end{array}$ & Prediction & $\begin{array}{l}\text { Lack of using FCM } \\
\text { extension }\end{array}$ & None & $\begin{array}{l}\text { (Takács, Rudas, } \\
\text { \& Lantos, } \\
\text { 2014)[7] }\end{array}$ \\
\hline $\begin{array}{c}\text { School } \\
\text { Educational } \\
\text { system }\end{array}$ & $\begin{array}{c}\text { Parameter } \\
\text { analysis of educational models }\end{array}$ & Prediction & $\begin{array}{c}\text { Manual } \\
\text { Lack of using FCM } \\
\text { extension }\end{array}$ & None & $\begin{array}{c}\text { (Bagány \& } \\
\text { Takács, 2017)[8] }\end{array}$ \\
\hline $\begin{array}{l}\text { Game-based } \\
\text { learning }\end{array}$ & Learning assessment & Diagnosis & $\begin{array}{l}\text { Manual } \\
\text { Lack of using FCM } \\
\text { extension }\end{array}$ & None & $\begin{array}{l}\text { (Baron, Rojas, } \\
\text { Diaz, \& } \\
\text { Contreras, } \\
\text { 2014)[9] }\end{array}$ \\
\hline Robotics & $\begin{array}{c}\text { Evaluate the effect of practical } \\
\text { courses on students' learning } \\
\text { achievement. }\end{array}$ & Interpretation & $\begin{array}{l}\text { Lack of using FCM } \\
\text { extension }\end{array}$ & None & $\begin{array}{l}\text { (Albayrak \& } \\
\text { Albayrak, } \\
\text { 2016)[10] }\end{array}$ \\
\hline Engineering & $\begin{array}{c}\text { Modeling Control } \\
\text { Engineering Program (CEP) critical } \\
\text { success factors }\end{array}$ & Modeling and decision-making & $\begin{array}{c}\text { Manual } \\
\text { Lack of using FCM } \\
\text { extension }\end{array}$ & None & $\begin{array}{l}\text { (Yesil, Ozturk, } \\
\text { Dodurka, \& } \\
\text { Sahin, 2013)[11] }\end{array}$ \\
\hline $\begin{array}{c}\text { Smart } \\
\text { Classroom }\end{array}$ & Learning resources recommender & Recommending & $\begin{array}{l}\text { Lack of using FCM } \\
\text { extension }\end{array}$ & None & $\begin{array}{l}\text { (Aguilar, } \\
\text { Valdiviezo-Díaz, } \\
\text { \& Riofrio, } \\
\text { 2016)[12] }\end{array}$ \\
\hline $\begin{array}{l}\text { University } \\
\text { organization }\end{array}$ & $\begin{array}{l}\text { Predicting the desirability and } \\
\text { number of student } \\
\text { applications to universities }\end{array}$ & $\begin{array}{l}\text { Prediction and decision- } \\
\text { making }\end{array}$ & $\begin{array}{l}\text { Manual } \\
\text { Lack of using FCM } \\
\text { extension }\end{array}$ & None & $\begin{array}{l}\text { (Nayak, P., } \\
\text { Madireddy, S., } \\
\text { Case, D. M., \& } \\
\text { Stylios, C. D. } \\
\text {,2017) [13] }\end{array}$ \\
\hline
\end{tabular}

\section{Discussion}

The development of an adaptive feedback environment and/or personalize tutoring requires the combination of pedagogical principles, domain attributes and various student's characteristics. The selection of appropriate student's characteristics is significant in the early stages of developing a student model. It is important to consider what aspect of the student characteristics is to be modelled according to the type of system developed [14]. In order to implement adaptation in a learning environment, it is necessary to model the flexibly stable, dynamic and domain dependent characteristics of the student [15]. The flexibly stable characteristics of the student includes cognitive styles, student's demographics, learning objectives and goals. The dynamic parameters are concerned with the student's interactions and experience with the learning environment. These characteristics include the student's errors and misconceptions, motivations, attitude, collaboration, learning actions and behaviours. The domain dependent characteristics of the student involves the student's knowledge level and interest in a specific topic.

FCM is used to represent knowledge which involves complex and uncertain processes. Knowledge is represented as graph, where the nodes represent concepts and the edge displays relationship between concepts. This technique provides a flexible means for knowledge representation and reasoning. Based on it's a dynamic nature, a change in one node affects other nodes. However, the nature of the nodes limits the adaptation of the edges. The relationships between the concepts are pre-defined and cannot change based on dynamic events within the adaptive learning environment. Past researchers have demonstrated that FCM provides a powerful technique in modeling domain knowledge in various scientific fields including education. Then again, FCM is highly dependent on expert's knowledge, which is often volatile [15]. An expert's help is needed to define the concepts and relationships strength between these concepts. This makes it very subjective to expert's opinion. In other words, the FCM-based model will be very subjective to domain knowledge of one (or in some cases of several experts). In practice, this affects the system capacity to model real-world problem by not choosing enough or relevant parameters or miscalculating the strength between the concepts. That is, the model will not be an accurate representation of real-world problem. For an FCM to successfully model complex real-world problems, it is crucial for the model to update itself in real-time, given the actual observed data through active learning approaches. In a similar vein, the process of building FCM is often difficult and expensive to expand while preserving the richness of its annotation. Also, dealing with more complex problems that include several different disciplines is even more challenging.

We believe that using an automated or semi-automated data-driven algorithm can eliminate or reduces the need for 
expert. It is important for the system to learn the relations in an unsupervised way rather than relying on an expert's intervention.

In order to overcome the limitations of conventional FCM models, it is very important to consider criteria such as non-linear relationship between concepts and time delay in the interaction between concepts by choosing appropriate FCM extension.

\section{v. Conclusion}

FCM ability to model causal complex problems with uncertain processes has attracted the attention of researchers from various scientific fields. In fact, there are numerous FCM applied in education researches. This paper presented a review of the application of FCMs within educational context over the past five years and discussed the limitations of the current applications and provides some directions for future improvement. These improvements include choosing appropriate FCM extension and learning algorithm for updating the weight of the relationships between concepts. Our future work focuses on the development of robust FCM learning algorithm for student modeling.

\section{Acknowledgment}

This work was supported by the University of Malaya Research Grant [RP040C-15AET].

\section{References}

[1] Kosko, B. (1986). Fuzzy cognitive maps. International journal of man-machine studies, 24(1), 65-75.

[2] Axelrod, R. (1976). Structure of decision: The cognitive maps of politicalelites: Princeton university press.

[3] Papageorgiou, E. I. (2012). Learning algorithms for fuzzy cognitive maps - a review study. IEEE Transactions on Systems, Man, and Cybernetics, Part C (Applications and Reviews), 42(2), 150-163.

[4] Chen, Y., Mazlack, L. J., \& Lu, L. J. (2012). Inferring fuzzy cognitive map models for gene regulatory networks from gene expression data. Paper presented at the Bioinformatics and Biomedicine (BIBM), 2012 IEEE International Conference on

[5] Papageorgiou, E. I., \& Salmeron, J. L. (2013). A review of fuzzy cognitive maps research during the last decade. IEEE Transactions on Fuzzy Systems, 21(1), 66-79.

[6] Chrysafiadi, K., \& Virvou, M. (2015). Fuzzy logic for adaptive instruction in an e-learning environment for computer programming. IEEE Transactions on Fuzzy Systems, 23(1), 164-177.

[7] Takács, M., Rudas, I. J., \& Lantos, Z. (2014). Fuzzy Cognitive Map for student evaluation model. Paper presented at the System Science and Engineering (ICSSE), 2014 IEEE International Conference on.

[8] Bagány, I., \& Takács, M. (2017). Soft-computing methods applied in parameter analysis of educational models. Paper presented at the Intelligent Systems and Informatics (SISY), 2017 IEEE 15th International Symposium on.

[9] Baron, H. B., Rojas, M. M., Diaz, J. T., \& Contreras, A. V. (2014). Graph Isomorphism in Fuzzy Cognitive Maps for Monitoring of Game-Based Learning. Paper presented at the Intelligent Networking and Collaborative Systems (INCoS), 2014 International Conference on.

[10] Albayrak, A., \& Albayrak, M. (2016). Performance evaluation of practice courses using fuzzy cognitive maps. Paper presented at the Information Technology Based Higher Education and Training (ITHET), 2016 15th International Conference on.

[11] Yesil, E., Ozturk, C., Dodurka, M. F., \& Sahin, A. (2013). Control engineering education critical success factors modeling via Fuzzy Cognitive Maps. Paper presented at the Information Technology Based Higher Education and Training (ITHET), 2013 International Conference on.
[12] Aguilar, J., Valdiviezo-Díaz, P., \& Riofrio, G. (2016). A fuzzy cognitive map like recommender system of learning resources. Paper presented at the Fuzzy Systems (FUZZ-IEEE), 2016 IEEE International Conference on.

[13] Nayak, P., Madireddy, S., Case, D. M., \& Stylios, C. D. (2017). Using fuzzy cognitive maps to model university desirability and selection. Paper presented at the Systems, Man, and Cybernetics (SMC), 2017 IEEE International Conference on

[14] González, C., Burguillo, J. C., \& Llamas, M. (2006). A qualitative comparison of techniques for student modeling in intelligent tutoring systems. Paper presented at the Frontiers in Education Conference, 36th Annual.

[15] Chrysafiadi, K., \& Virvou, M. (2013). A knowledge representation approach using fuzzy cognitive maps for better navigation support in an adaptive learning system. SpringerPlus, 2(1), 81 